\title{
A PRODUÇÃO CIENTÍFICA SOBRE EMPREENDEDORISMO TECNOLÓGICO: UM ESTUDO BIBLIOMÉTRICO
}

Larissa Soares $^{1}$

Matheus Augusto Celestino Santos Almeida ${ }^{1}$

Iracema Machado De Aragão Gomes ${ }^{1}$

${ }^{1}$ Universidade Federal de Sergipe 


\section{A PRODUÇÃO CIENTÍFICA SOBRE EMPREENDEDORISMO TECNOLÓGICO: UM ESTUDO BIBLIOMÉTRICO}

Resumo: O conceito de empreendedorismo tecnológico vai além de um produto da relação entre empreendedorismo e inovação, contudo, por ser um campo de estudo emergente, o mesmo possui um acervo reduzido de publicações. O presente trabalho propõe-se a delinear uma descrição das produções científicas sobre empreendedorismo tecnológico, nos últimos 10 anos, em periódicos da base de dados da Coordenação de Aperfeiçoamento de Pessoal de Nível Superior (CAPES). A pesquisa baseia-se na revisão bibliométrica de 30 artigos científicos no setor de Tecnologia da Informação e Comunicação (TIC) categorizados no período de 2006 a 2016, além de estruturar-se em mais seis seções. Dentre outros aspectos, relatou-se que a publicação de estudos relacionados ao empreendedorismo tecnológico no período analisado é não linear, os trabalhos que possuem dois ou três autores somam cerca de 66,67\% e a análise dos artigos possibilitou a identificação de citações e co-citações.

Palavras-chave: Bibliometria. Produção Científica. Empreendedorismo Tecnológico. 


\section{Introdução}

O contexto empreendedor é por vezes considerado multifacetado, sendo composto por níveis de análise e influência direta ou indireta dos ambientes social e mercadológico que contribuem para o surgimento de negócios (Welter, 2011). Desta forma, a atividade empreendedora pode ser vista como um processo diretamente influenciado pelo ambiente econômico e político do estado, sendo fortemente associado aos resultados de crescimento econômico provenientes da atividade comercial e, mais especificamente, do desenvolvimento de inovações (Giriuniene, Giriunas \& Cernius, 2016). Para Shane e Venkataraman (2000), o empreendedorismo se caracteriza como um fenômeno de processos de descoberta e/ou de oportunidades a serem avaliadas e exploradas pelo conjunto de indivíduos inseridos no contexto ambiental. Assim, por meio das noções de oportunidade e descoberta, os conceitos de empreendedorismo e inovação têm sido fortemente relacionados (Autio, Kenney, Mustar, Siegel \& Wright, 2014).

Nesse sentido, o empreendedorismo inovador surge da proposta de Schumpeter (1934) de destruição criativa, à medida que estabelece a ponte entre a criação de novos produtos, serviços e processos e a comercialização destes, modificando o status quo econômico. De acordo com Autio et al. (2014) o empreendedorismo inovador envolve a interrupção das indústrias existentes e a criação de novas, em um contexto de políticas de estímulo. Consequentemente, para os autores, os negócios inovadores estão associados a um cenário de empreendedorismo e transferência tecnológica, já que exemplos recentes de empreendedorismo inovador surgem nos setores de biotecnologia, engenharia, tecnologia da informação e ecommerce (Autio et al., 2014; Ferreira et al., 2016). Tal percepção corrobora o desenvolvimento de empreendedorismo tecnológico como uma das muitas vertentes provenientes da relação entre empreendedorismo e inovação.

De acordo com Petti e Zhang (2011), o empreendedorismo tecnológico não envolve simplesmente a criação e o desenvolvimento de tecnologias, mas o conjunto de atores e ações empresariais que transformam e introduzem rapidamente tais tecnologias no mercado, por meio de novos produtos e/ou processos. Entretanto, o conceito deste tipo de empreendedorismo torna-se mais complexo do que a descrição dada pelos autores, em detrimento do cenário inovador e constantemente mutável da sociedade em rede.

Ferreira et al. (2016) declaram que o empreendedorismo tecnológico (TE) é um campo teórico emergente, em especial pelo número ainda restrito de publicações. Ratinho, Harms \& Walsh (2015) corroboram esta ideia ao considerar que as pesquisas em TE são interdisciplinares, mas, apesar de estarem conseguindo popularidade em diversos periódicos, a relevância dos estudos presentes na comunidade acadêmica é decrescente.

$\mathrm{O}$ avanço das tecnologias de informação e comunicação tem estimulado o empreendedorismo tecnológico como capacidade de resposta aos desafios contemporâneos, sendo percebido como um campo de interesse crescente para a atuação mercadológica (Guimaraes \& Azambuja, 2010; Spiegel \& Marxt, 2011; Colovic \& Lamotte, 2015). Desta forma, nas últimas décadas, a motivação em torno do fenômeno é perceptível tanto em investigadores acadêmicos como em dirigentes políticos, por meio do impacto significativo das atividades no progresso econômico (Mosey, Guerrero \& Greenman, 2017).
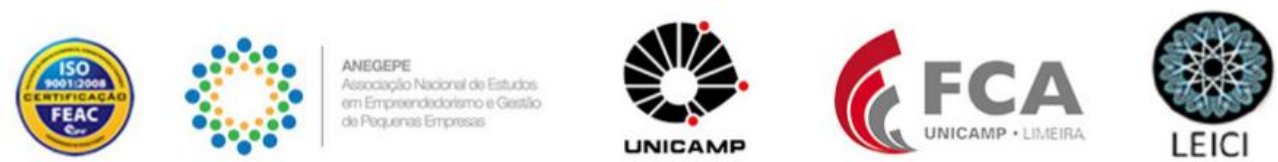
$\mathrm{Na}$ discussão do crescimento das pesquisas voltadas para o empreendedorismo tecnológico, este estudo busca delinear uma descrição das produções científicas sobre empreendedorismo tecnológico, nos últimos 10 anos, em periódicos da base de dados da Coordenação de Aperfeiçoamento de Pessoal de Nível Superior (CAPES). Metodologicamente, o estudo baseia-se em uma revisão bibliométrica de 30 artigos científicos categorizados no período de 2006 a 2016, onde há aplicação de técnicas estatísticas para a descrever aspectos literários e avaliar a produção científica de um campo (Araújo, 2006). Ademais, o enfoque deste artigo é abordar o empreendedorismo tecnológico apenas no setor de Tecnologia da Informação e Comunicação (TIC), cuja relevância corrobora nas capacidades empresariais de identificar e explorar oportunidades tecnológicas para criar produtos novos ou significativamente melhorados e comercializá-los com sucesso (Petti \& Zhang, 2011).

O artigo está estruturado em mais seis seções. A segunda seção apresenta uma visão geral do empreendedorismo. A terceira seção enfatiza as conceptualizações de empreendedorismo inovador. A quarta seção discute o contexto geral da literatura sobre empreendedorismo tecnológico. A quinta seção apresenta a metodologia utilizada para a investigação bibliométrica. A sexta seção discute os resultados em termos de áreas centrais de pesquisa, identificação de ano de publicação, periódicos, universidades e autores, além de uma breve comparação com os achados de Ferreira et al (2016) e Bailetti (2012). Assim, a sexta e última seção aborda as conclusões e observações acerca dos achados e traz indícios para pesquisas futuras.

\section{Empreendedorismo}

Primeiramente, acerca do conceito de empreendedorismo, Howard Stevenson (1983) destaca que o mesmo é o processo pelo qual os atores buscam oportunidades num determinado ambiente, contudo, sem considerar os recursos que possuem no momento. Porém, na visão de Venkataraman (1997), o empreendedorismo é visto como um exame acadêmico acerca da forma como as oportunidades são dimensionadas para criar bens e serviços futuros, ou seja, como as oportunidades são identificadas, analisadas e utilizadas.

O empreendedorismo é um fenômeno de grande importância em termos de porte empresarial, ajudando a incentivar a competição (Soriano \& Huarng, 2013). Schumpeter (1934) considera o empreendedorismo, na relação entre inovação, criação de mercados e ação empreendedora, como um processo de "destruição criativa", onde o desenvolvimento econômico está diretamente relacionado a substituição de antigos hábitos de consumo por novos. Assim, o empreendedor incita a mudança econômica, na alteração do status quo, por meio de inovações radicais ou incrementais (Spiegel \& Marxt, 2011; Binnui \& Cowling, 2016).

Além disso, muitas pesquisas sobre o empreendedorismo ainda utilizam contextos que são fáceis de operacionalizar e observar, como o contexto empresarial (Klapper, Lewin \& Delgado, 2009), e que se encaixam no modelo do indivíduo empreendedor, como aparente em um levantamento dos estudos sobre empreendedorismo (Minniti, 2003).

Além disso, nota-se que as pesquisas sobre empreendedorismo apresentam que as questões sociodemográficas, ocupacionais e características psicológicas do empreendedor
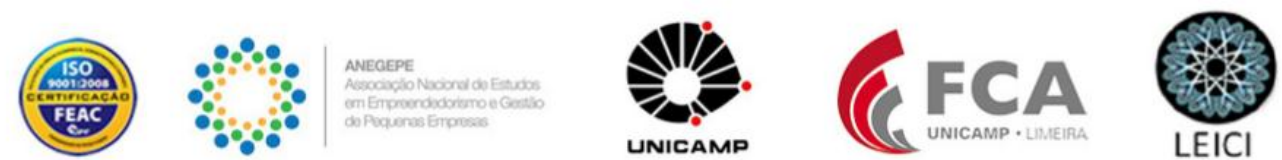
influenciam o processo de identificação de oportunidades e exploração (Shane \& Venkataraman, 2000).

Além disso, a forma como o empreendedorismo é analisado nos permite categorizá-lo ao prestar atenção aos níveis de análise mais baixos e mais altos (Hackman, 2003). Assim, algumas pesquisas concentraram-se na natureza do empreendedorismo em contexto das pequenas empresas (Carter, 1998; Carter, Tagg, \& Dimitratos, 2004), mostrando como o empreendimento de portfólio e a pluritividade aumentam os rendimentos e facilitam entrada ou saída de negócios.

Seguidamente, o empreendedorismo pode ser visto como um evento coletivo em um contexto espacial particular, o ambiente local, embora alguns autores ultrapassem os limites locais ao identificar os governos nacionais como atores nesse sentido (Dupuis \& de Bruin, 2003).

Além disso, o empreendedorismo é um meio eficiente para promover a mudança social, como ilustrado por Johnstone e Lionais (2004) para empresas comunitárias, que promovem o desenvolvimento econômico e social em comunidades em situações precárias e, portanto, o empreendedorismo vai além do lucro para o empreendedor, ele gera riqueza para região em que está situado e, assim, promove mudanças sócio/econômicas.

No entanto, o próprio empreendedorismo também influencia alguns contextos, como mostrado em Feldman, Francis e Bercovitz (2005), que analisam o papel que o empreendedorismo desencadeia no surgimento de aglomerações de alta tecnologia, ou por Boettke e Coyne (2009), que estudam os dois: relação entre instituições e empreendedorismo.

Assim, o contexto contribui para explicar motivos de alguns empreendedores poderem reconhecer oportunidades e outros não e por que os resultados das atividades empresariais podem variar em diferentes países, regiões e outros contextos (Baker, Gedajlovic \& Lubatkin, 2005)

Portanto, os pesquisadores do empreendedorismo devem reconhecer que o empreendedorismo acontece em vários contextos e que a pesquisa do empreendedorismo ocorre em contextos e comunidades específicas, ou seja, explora as várias comunidades intelectuais que surgem no campo do empreendedorismo (Gartner, Davidsson \& Zahra, 2006).

\section{Empreendedorismo Inovador}

Como todas as formas de empreendedorismo, o empreendedorismo inovador é resultado de uma relação contínua entre indivíduos e o ambiente, ou seja, a descoberta e aproveitamento de novas oportunidades (Shane, 2003). Diante do paradigma da tecnologia da informação, a atividade empreendedora envolve as criações e descobertas que impulsionam oportunidades de negócio e desenvolvimento econômico (Ferreira et al, 2016). Galindo e Méndez (2014) afirmam que a inovação é inerente ao desenvolvimento humano, obtendo sucesso nas mudanças comportamentais sociais. Nesse sentido, a inovação e o conhecimento tornam-se fatores de sustentabilidade, produtividade e geração de riqueza (Guimaraes \& Azambuja, 2010).

O processo de inovação é tradicionalmente considerado como a difusão do conhecimento, sendo um fator-chave de desenvolvimento empresarial e impulsionador do crescimento econômico (Galindo \& Méndez, 2014, Binnui \& Cowling, 2016).
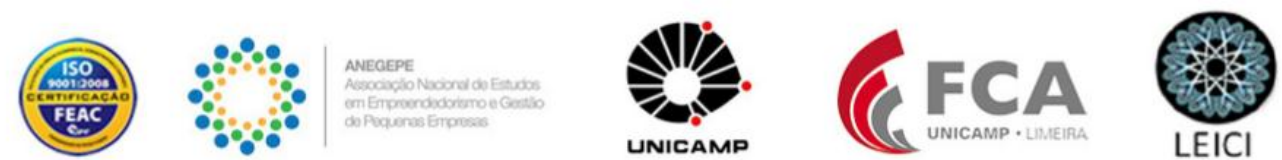
A abordagem schumpeteriana associa então as figuras do empreendedor e do inovador como similares, permeando a intenção e o desenvolvimento da ação comercial (Ferreira et al, 2016, Soriano \& Huarng, 2013). Entretanto, a inovação atua como uma variável exógena, ou seja, uma ferramenta para os empreendedores no processo de mensuração das oportunidades de negócio (Soriano \& Huarng, 2013).

Seguidamente, acerca do empreendedorismo, os empreendedores operam em mercados emergentes ou desafiam as empresas existentes em mercados estabelecidos. Portanto, isso os torna susceptíveis de desenvolver outras formas de comportamento ou de estratégia do que outros empreendedores ou outros tipos de start-ups (Samuelsson \& Davidsson, 2009).

Conseguinte, sobre os benefícios do empreendedorismo inovador, ele pode ser uma fonte de geração de riqueza individual e, também, regional, dessa forma, além de ser benéfico para o empreendedor, esse empreendedorismo pode gerar progresso social (Schumpeter, 1942). Pesquisas anteriores sobre educação de empreendedorismo e seus efeitos tinham foco apenas no empreendedorismo, mas não trataram o empreendedorismo inovador como uma categoria separada (Walter \& Block, 2016). Contudo, como mostra a nossa literatura, o empreendedorismo inovador é diferente de outras formas de empreendedorismo, envolve diferentes atores (empresários, inventores, empresários acadêmicos, funcionários) e requer habilidades diferentes.

Muitos teóricos debatem o sucesso e o fracasso do empreendedorismo inovador por meio de fatores diversos, tais como, capital humano, internacionalização, propriedade institucional e geração de empregos (Binnui \& Cowling, 2016). Para Galindo e Méndez (2014), o processo de inovação consiste no crescimento e aumento dos lucros, sendo incentivado e facilitado pelo clima social que permite atenuar as consequências negativas da substituição do trabalho humano pela tecnologia, pela redução do estresse e pela atividade econômica positiva. Enfim, o comportamento social pode facilitar ou desencorajar o processo de inovação, através dos agentes econômicos, fomentando a competitividade e a introdução dos bens de consumo no mercado (Binnui \& Cowling, 2016).

\section{Empreendedorismo Tecnológico}

O desenvolvimento tecnológico e seus efeitos sobre a atividade empresarial continuam a ser um objeto de estudo pertinente e moderno, já que a adoção da tecnologia de informação tornou-se um aspecto cotidiano (Soriano \& Huarng, 2013). Nesse sentido, o surgimento e a promoção das empresas baseadas em tecnologia é o alicerce das políticas industriais avançadas (Brown \& Mason, 2014) e, portanto, o empreendedorismo e a tecnologia são fontes cruciais para a sobrevivência e crescimento organizacional, por meio da iniciativa humana (Binnui \& Cowling, 2016; Ferreira et al, 2016).

O setor de tecnologia é onde o empreendedorismo tecnológico (TE) tem maior probabilidade de ocorrência pela sensibilidade dos atores no setor de Tecnologia da Informação, onde as velozes mudanças tecnológicas e ao valor de mercado, pois as TICs promovem a criação de novos empreendimentos, mudando radicalmente o relacionamento entre empreendedorismo e inovação (Colovic \& Lamotte, 2015).

$\mathrm{O}$ empreendedorismo tecnológico vêm sendo debatido por muitos pesquisadores em diversas correntes teóricas, porém, do mesmo modo que o conceito de empreendedorismo ainda

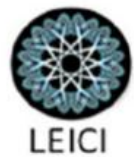


não é comensurável, o conceito de TE surge de uma visão multidimensional que envolve diversos atores e níveis de análise, consistindo na criação de empreendimentos que podeminstituir prosperidade para indivíduos, organizações e regiões (Mosey, Guerrero \& Greenman, 2017; Ratinho, Harms \& Walsh, 2015; Bailetti, 2012). Entretanto, para Petti e Zhang (2011) o empreendedorismo tecnológico pode ser facilmente identificado pela transformação de tecnologias promissoras em oportunidades de valor comercial.

Mosey, Guerrero \& Greenman (2017) apontam que diversos autores têm definido o empreendedorismo tecnológico pela relação com a inovação, sendo considerada um instrumento específico do empreendedorismo (Soriano \& Huarng, 2013). Outras inferências conceituas são propostas nos estudos de Spiegel \& Marxt (2011), que sugere um enquadramento de TE em decorrência das fases do processo empreendedor em diferentes níveis, e Bailetti (2012), em decorrência das vertentes observadas na pesquisa bibliométrica. Já as análises empíricas examinam o tema em vários níveis de análise, incluindo o empreendedor, a nova empresa, a indústria e a tecnologia (Shane \& Venkataraman, 2003).

Assim como a produção acadêmica, o desenvolvimento de empresas baseadas em tecnologia tem certa concentração em consequência do acesso à infraestrutura de TIC e o investimento em pesquisa e desenvolvimento (P\&D) que influencia a probabilidade de TE regional e ameniza a imitabilidade dos recursos e das inovações (Colovic \& Lamotte, 2015; Venkataraman, 2004). Desta forma, o contexto ambiental no qual a atividade empreendedora é manifesta deve ser analisado cuidadosamente na formulação de explicações sobre o TE (Shane \& Venkataraman, 2003).

De modo geral, a política da economia da informação em diversos países pode ser categorizada pela missão, com ênfase em projetos de descobertas científicas, ou pela difusão, com ênfase no desenvolvimento empresarial e adaptação as novas tecnologias (Brown \& Mason, 2014), implicando nas configurações do TE regional. Nesse sentido, Ratinho, Harms e Walsh (2015) declaram que o empreendimento tecnológico obtém vantagem competitiva pelo reconhecimento das possibilidades tecnológicas e pela capacidade de uso de produtos tecnológicos paradigmáticos para fornecer soluções mercadológicas.

Portanto, além dos aspectos de transformação regional, o TE possui vários enfoques inter-relacionados. Bailetti (2012) distingue o empreendedorismo tecnológico de outros tipos de empreendedorismo pela experimentação colaborativa e pela produção de bens relacionados ao avanço do conhecimento científico e tecnológico e aos direitos de propriedade intelectual da empresa, de modo que a mudança tecnológica influencia as estratégias de criação e captação de valor. Outra distinção é o gerenciamento de tecnologia para reduzir incertezas e fluxos de conhecimento (Shane \& Venkataraman, 2003). Deste modo, o investimento em P\&D se institui como uma fronteira entre a destruição criativa (Schumpeter, 1934) por meio da introdução de invenções tecnológicas e a taxa de inovação (Colovic \& Lamotte, 2015).

Para Spiegel \& Marxt (2011), o empreendedorismo tecnológico investiga todas as questões processuais em termos de formação, exploração e renovação de produtos/serviços e os processos em empresas de base tecnológica novas ou estabelecidas. Deste modo, os pesquisadores averiguam como as empresas voltadas à tecnologia constituem, sustentam e expandem seu posicionamento competitivo. A definição de Bailetti (2012) sugere que empreendedorismo tecnológico é um projeto de investimento que reúne e distribui indivíduos especializados e ativos heterogêneos, relacionados com os avanços no conhecimento científico-

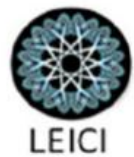


tecnológico, e que objetivam a captura de valor empresarial. O autor também aponta cinco definições de TE nas quais as pesquisas analisadas sugerem a categorização do fenômeno, sendo: operar pequenas empresas de engenheiros ou cientistas, encontrar problemas ou aplicações em uma tecnologia, introduzir empreendimentos, aplicações ou exploração de oportunidades em detrimento dos conhecimentos científicos e técnicos e trabalhos colaborativos na produção de mudanças tecnológicas.

Em suma, o TE pode ser definido pela mensuração de oportunidades de negócio, reunindo recursos em torno de uma solução tecnológica (Ratinho, Harms \& Walsh, 2015; Petti \& Zhang, 2011). Neste caso, a atividade empreendedora não se restringe a especulação, mas engloba o processo criativo e interpretativo no qual diversos atores estão inseridos e onde há suporte tecnológico, dando origem as estruturas de conhecimento para reorganização e transformação dos recursos existentes (Ferreiraet al, 2016). Apesar de Spiegel e Marxt (2011) defenderem que uma definição rigorosa de escopo e uma agenda de pesquisa devem ser elaboradas, para Mosey, Guerrero \& Greenman (2017), mais importante do que o debate conceitual é a definição dos melhores métodos para investigação, análise e compartilhamento dos achados das pesquisas sobre o crescimento do empreendedorismo tecnológico por meio de duas vertentes: oportunidades no nível individual e organizacional e interações entre os níveis organizacional e ambiental.

\section{Metodologia}

O presente estudo objetiva explorar a produção científica da última década sobre empreendedorismo tecnológico através da base de periódicos da Coordenação de Aperfeiçoamento de Pessoal de Nível Superior (CAPES), verificando assim o nível de atividade em determinado campo/domínio científico (Ferreira et al, 2016). A base de periódicos utilizada conta com mais de 39 mil títulos de periódicos com texto completo, 134 bases referenciais e 11 bases dedicadas a patentes disponíveis para as Instituições de Ensino Superior e de Pesquisa no Brasil (CAPES, 2017).

Nesse sentido, a pesquisa se caracteriza como exploratória e descritiva, pois apresenta um determinado fenômeno e avaliar as relações entre as variáveis componentes do mesmo (Sampieri, Collado e Lúcio, 2006; Creswell, 2010). Além disso, a pesquisa também pode ser definida tendo em vista uma abordagem quantitativa, já que se trata de uma análise bibliométrica; técnica que envolve o levantamento estatístico das publicações, citações e informações disseminadas e registradas, em um determinado período de tempo, para identificação de tendências de pesquisa e de relações com as temáticas de inovação (Araújo, 2006; Cruz, Marques, Silva \& Cogan, 2010, Ribeiro \& Corrêa, 2014).

Assim, a coleta de dados realizada na base de Periódicos CAPES, utilizou os termos "high-tec entrepreneurship" e "technological entrepreneurship" para busca no título ou nas palavras-chave dos estudos, estabelecendo como corte temporal o período de 2006 a 2016.

O levantamento inicial resultou em 153 artigos, sendo refinados na eliminação de estudos repetidos e publicações não provenientes de revistas que utilizam revisão por pares. Desta forma, a amostra utilizada resultou em 30 artigos, uma quantidade inferior aos achados de Ferreira et al (2016) cuja pesquisa bibliométrica investigou 135 artigos científicos entre 1986 e 2013, encontrando 90 publicações entre 2006 e 2013. Entretanto, tal diferença amostral ocorre

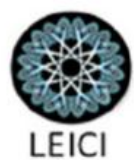


pelo enfoque deste trabalho em publicações de empreendedorismo tecnológico que enfatizem as TICs. Assim, considera-se que o valor amostral encontrado é relevante e expressivo, dentro das limitações objetivadas.

Os dados coletados nos 30 artigos foram então submetidos a consolidação de informações por meio do Microsoft Excel, permitindo a elaboração de gráficos e tabelas dos resultados apresentados na próxima seção.

\section{Resultados e Discussões}

Os 30 artigos encontrados e selecionados foram analisados quanto ao ano de publicação, periódico no qual foi publicado, quantidade de autores e palavras-chave mais utilizadas, além da distinção entre estudo empírico e ensaio teórico e estudos mais frequentemente citados. Nesse sentido, a tabela 1 demonstra o delinear das publicações no recorte temporal escolhido, a quantidade de publicações em cada revista (frequência relativa) e o parâmetro de classificação da CAPES para artigos publicados em periódicos científicos (QUALIS).

\begin{tabular}{|c|c|c|c|c|c|c|c|c|c|c|c|c|}
\hline Periódico & Qualis & 2006 & 2007 & 2008 & 2009 & 2010 & 2011 & 2012 & 2013 & 2014 & 2015 & 2016 \\
\hline $\begin{array}{l}\text { Economic Development } \\
\text { Quarterly }\end{array}$ & ----- & - & - & - & - & - & 1 & - & - & - & - & - \\
\hline $\begin{array}{l}\text { Entrepreneurship } \\
\text { Theory And Practice }\end{array}$ & A1 & - & 2 & - & - & - & - & - & 1 & - & 1 & - \\
\hline $\begin{array}{l}\text { Frontiers of Business } \\
\text { Research in China }\end{array}$ & ----- & - & - & - & - & - & 1 & - & - & - & - & - \\
\hline $\begin{array}{l}\text { International } \\
\text { Entrepreneurship and } \\
\text { Management Journal }\end{array}$ & A1 & - & 1 & 1 & - & - & - & - & 1 & 1 & - & - \\
\hline $\begin{array}{l}\text { Journal of Business } \\
\text { Research }\end{array}$ & A1 & - & - & - & - & - & - & - & 1 & - & - & - \\
\hline $\begin{array}{l}\text { Journal of Chineses } \\
\text { Entrepreneurship }\end{array}$ & ----- & - & - & - & - & - & 1 & - & - & - & - & - \\
\hline $\begin{array}{l}\text { Journal of } \\
\text { Entrepreneurship, } \\
\text { Management And } \\
\text { Innovation }\end{array}$ & ----- & - & - & - & - & - & - & 1 & - & - & - & - \\
\hline $\begin{array}{l}\text { Journal of Industrial } \\
\text { Engineering }\end{array}$ & ----- & 1 & - & - & - & - & - & - & - & - & - & - \\
\hline $\begin{array}{l}\text { Journal of International } \\
\text { Entrepreneurship }\end{array}$ & A2 & - & - & - & - & - & - & - & 1 & - & - & - \\
\hline $\begin{array}{l}\text { Journal of Small } \\
\text { Business And Enterprise } \\
\text { Development }\end{array}$ & ----- & - & - & 1 & 1 & - & - & - & - & - & - & - \\
\hline $\begin{array}{l}\text { Journal of Technology } \\
\text { Management \& } \\
\text { Innovation }\end{array}$ & $\mathrm{A} 2$ & - & - & - & - & - & - & - & - & - & - & 1 \\
\hline $\begin{array}{l}\text { Journal of Technology } \\
\text { Management In China }\end{array}$ & ------ & - & - & - & - & - & - & 1 & - & - & - & - \\
\hline
\end{tabular}




\begin{tabular}{|c|c|c|c|c|c|c|c|c|c|c|c|c|}
\hline $\begin{array}{l}\text { Measuring Business } \\
\text { Excellence }\end{array}$ & ---- & - & - & - & - & - & - & - & 1 & - & - & - \\
\hline $\begin{array}{l}\text { Public Administration } \\
\text { Review }\end{array}$ & A1 & - & - & - & 1 & - & - & - & - & - & - & - \\
\hline Sociedade e Estado & B1 & - & - & - & - & 1 & - & - & - & - & - & - \\
\hline $\begin{array}{l}\text { Small Business } \\
\text { Economics }\end{array}$ & --- & - & - & - & - & - & - & - & - & 2 & - & 1 \\
\hline $\begin{array}{l}\text { Technological } \\
\text { Forecasting \& Social } \\
\text { Change }\end{array}$ & A1 & - & - & - & - & - & - & - & - & - & 1 & \\
\hline Technovation & $\mathrm{A} 1$ & - & - & 1 & - & - & - & - & - & 1 & - & - \\
\hline The World Economy & ----- & - & - & - & - & - & - & 1 & - & - & 1 & - \\
\hline Total & & 1 & 3 & 3 & 2 & 1 & 4 & 2 & 5 & 4 & 3 & 2 \\
\hline
\end{tabular}

Tabela 1 - Distribuição de artigos por ano e por periódico

Fonte: Elaborado pelos autores (2018).

Percebe-se que a publicação de estudos relacionados ao empreendedorismo tecnológico no período analisado é não linear, havendo picos e declínios na quantidade de estudos ao longo dos anos. Consequentemente, os anos de $2011(\mathrm{fr}=4)$ e 2013 ( $\mathrm{fr}=5$ ) podem ser considerados como anos de maior frequência quanto ao número de publicações. De 2013 a 2016 ocorre então um declínio constante no número de artigos o que pode inferir uma saturação de estudos da área. De qualquer forma, Ferreira, Reis e Miranda (2015) indicam o empreendedorismo tecnológico como um dos temas mais pesquisados no campo de empreendedorismo e a pesquisa de Ferreira et al. (2016) também apresentou grandes oscilações no número de publicações por ano o que permite pensar no comportamento dos dados para o corte temporal indicado como dentro da normalidade para o contexto da área de TE.

Os periódicos Entrepreneurship Theory and Practice e International Entrepreneurship and Management Journal destacam-se com a publicação de quatro artigos (fr\% $=26,66)$ cada, seguido pelos periódicos Small Business Economics com três artigos (fr\% $=10)$ e Journal of Small Business and Enterprise Development, Technovation e The World Economy com dois artigos (fr\% $=13,34)$ cada. Tais periódicos representam aproximadamente $54 \%$ da amostra pesquisada e podem ser considerados como os mais influentes para publicação de estudos sobre empreendedorismo tecnológico. Além disso, quatro dentre os 19 periódicos listados já foram identificados por Ratinho, Harms \& Walsh (2015) como relevantes para a pesquisa em TE: Technovation, Small Business Economics, Technological Forecasting and Social Change e Entrepreneurship Theory and Practice.

No tangente a classificação QUALIS referenciada para cada periódico segue os estrados indicativos de qualidade: A1 (mais elevado), A2, B1, B2, B3, B4, B5, C (peso zero). Os estrados são indicados em concordância com as áreas de avaliação da CAPES, sendo utilizado como parâmetro na tabela 1 a classificação dos periódicos para a área de Administração Pública e de Empresas, Ciências Contábeis e Turismo. Nesse sentido é válido ressaltar que classificações foram encontradas para os periódicos Journal of Small Business and Enterprise Development (B2) e Measuring Business Excellence (B3) nas áreas Interdisciplinar e Engenharia respectivamente. De acordo com a CAPES (2017), a estratificação da qualidade é embasada na produção intelectual dos programas de pós-graduação brasileiros e passa por um processo anual de atualização. Diante disso, periódicos apresentados na tabela 1 sem tal classificação podem

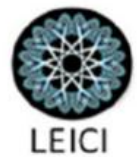


indicar a inexistência, até o momento, de estudos publicados e realizados por pesquisadores brasileiros para a área supracitada.

Com relação ao número de autores em cada artigo, destaca-se a elaboração de trabalhos em pares ou trios. Nota-se que os trabalhos que possuem dois ou três autores somam cerca de $66,67 \%$ ( $n=22$ artigos), enquanto que os artigos com um único autor representam 26,67\% ( $\mathrm{n}=8$ artigos) e trabalhos com quatro autores representam $6,67 \%(n=2$ artigos) da amostra. Já as palavras-chave mais utilizadas pelos pesquisadores são listadas na tabela 2 que faz alusão as 10 palavras mais frequentemente adotadas em ordem decrescente.

\begin{tabular}{l|c|l|c}
\hline \multicolumn{1}{c|}{ PALAVRAS - CHAVE } & Fr & \multicolumn{1}{|c}{ PALAVRAS - CHAVE } & Fr \\
\hline Innovation & 5 & Innovation Systems Entreprenership & 3 \\
\hline China & 4 & Public Policy & 2 \\
\hline Entrepreneurialism & 4 & SME (Small And Medium Enterprise) & 2 \\
\hline Entrepreneurship & 4 & Technological Entrepreneurship & 4 \\
\hline High Technology & 3 & Technology-Led Strategy & 2 \\
\hline
\end{tabular}

Tabela 2 - Palavras-chave mais utilizadas

Fonte: Elaborado pelos autores (2018).

O uso de palavras-chave permite averiguar de forma sucinta o enfoque dos estudos investigados. Dentre as palavras-chave listadas na tabela 2 destacam-se aqueles que foram citadas quatro vezes ou mais na análise dos 30 artigos: Innovation; China; Entrepreneurialism; Entrepreneurship e Technological Entrepreneurship. As palavras identificadas também podem ser agrupadas em termos de referências a inovação (Innovation; Innovation Systems Entreprenership), empreendedorismo (Entrepreneurialism; Entrepreneurship), tecnologia e/ou empreendedorismo tecnológico (High Technology; Technological Entrepreneurship; Technology-Led Strategy) e referências particulares (China; Public Policy; SME). Desta forma, temos uma frequência de sete referências a inovação, oito referências ao empreendedorismo, dez referências a tecnologia e/ou empreendedorismo tecnológico e oito referencias com enfoques particulares. Esses achados fortalecem as noções associativas entre inovação e empreendedorismo tecnológico, remetem as possibilidades de TE para empresas de pequeno e médio porte, as possíveis relações com as políticas públicas de uma nação e a evidência de práticas empreendedoras relacionadas à tecnologia na China, conforme também demonstrado na listagem de periódicos onde três dos 19 periódicos listados enfatizam o empreendedorismo chinês (Frontiers of Business Research in China, Journal of Chineses Entrepreneurship e Journal of Technology Management in China).

Para além da discussão das palavras-chave os artigos foram categorizados como produção teórica, uso de dados secundários ou pesquisa empírica. Nesse sentido, foram identificados sete estudos teóricos que buscavam discutir conceitualmente o empreendedorismo tecnológico e sua estrutura, relacionar o fenômeno com o capital humano, as políticas nacionais, a orientação empresarial ou as questões culturais. Um estudo com base em dados secundários fornecidos por relatórios internacionais de empreendedorismo foi identificado e os demais 22 estudos empíricos da amostra enfatizavam perspectivas nacionais. Assim, frequências percentuais sobre as nações enfocadas nas pesquisas de empreendedorismo tecnológico podem ser visualizadas na figura 1 .

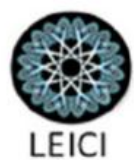




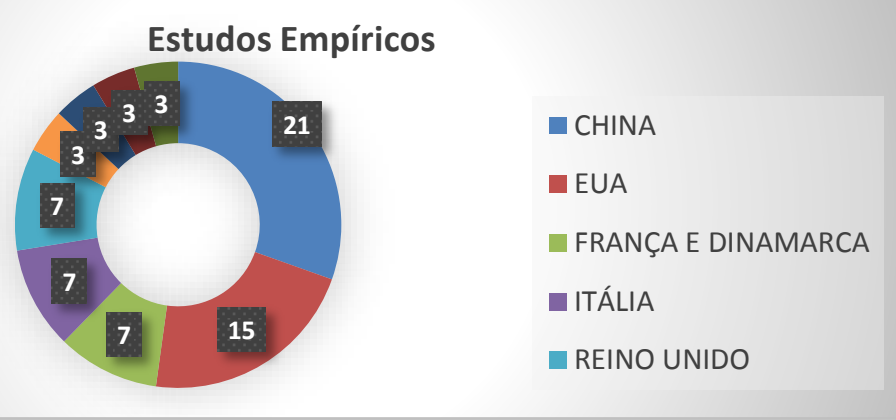

Figura 1 - Enfoque dos Estudos Empíricos

Fonte: Elaborado pelos autores (2018).

Das 22 publicações empíricas que enfocaram perspectivas do empreendedorismo tecnológico em determinado país, em concordância com os achados para a frequência das palavras-chave e periódicos com enfoque em atividades empresariais chinesas, a China foi investigada por 6 estudos ( $20 \%$ da amostra total). Em seguida, são identificados 5 trabalhos que investigam o empreendedorismo tecnológico nos Estados Unidos (17\% da amostra total), dois trabalhos sobre TE na França e/ou Dinamarca, dois na Itália e dois no Reino Unido, totalizando seis pesquisas (21\%), e um trabalho para cada um dos demais países citados (Brasil, Irlanda, México, Eslovênia e África do Sul). Esses resultados apontam para a diversidade de ambientes onde o empreendedorismo tecnológico pode ocorrer e o potencial para o desenvolvimento de TE dos países supracitados.

Por fim, a análise dos artigos possibilitou a identificação de citações e co-citações, ou seja, a verificação dos trabalhos mais referenciados. Consequentemente, a tabela 3 apresenta os 30 estudos mais citados em ordem alfabética e a frequência de citação.

\begin{tabular}{l|c|l|c}
\hline \multicolumn{1}{c|}{ Autores } & $\begin{array}{c}\text { Quantidade } \\
\text { de Citações }\end{array}$ & \multicolumn{1}{c}{ Autores } & $\begin{array}{c}\text { Quantidade } \\
\text { de Citações }\end{array}$ \\
\hline Antonic \& Prodan (2008)* & 7 & Lumpkin \& Dess (1996)* & 7 \\
\hline Bahrami \& Evans, S. (1995)* & 5 & Lundvall (1992) & 4 \\
\hline Burt (1992)* & 3 & Miller (1983)* & 5 \\
\hline Chen \& Yuan (2007) & 11 & North (1990)* & 5 \\
\hline Cohen \& Levinthal (1990)* & 8 & Phan \& Foo (2004)* & 6 \\
\hline Colombo \& Grilli (2005) & 5 & Porter (1990) & 5 \\
\hline Covin \& Slevin (1991) & 5 & Schumpeter (1942) * & 5 \\
\hline Dobson \& Safarian (2008) & 5 & Shane \& Venkataraman (2000) * & 9 \\
\hline Doganova \& Eyquem-Renault (2009) * & 3 & Shane \& Venkataraman (2003) * & 8 \\
\hline Elfring \& Hulsink (2003) & 5 & Shane (2003) * & 8 \\
\hline Gans \& Stern (2003) & 9 & Spencer, Murtha \& Lenway (2005) * & 5 \\
\hline
\end{tabular}




\begin{tabular}{l|l|l|c} 
Hindle \& Yencken (2004) & 8 & Stinchcombe (1965)* & 3 \\
\hline Kenney \& Burg (1999) & 7 & Teece (2007) * & 4 \\
\hline Kirzner (1973)* & 4 & Teece, Pisano \& Shuen (1997) & 5 \\
\hline Liu (2008) & 13 & Xie \& White (2006) & 9 \\
\hline
\end{tabular}

Tabela 3 - Citações e Co-citações

Fonte: Elaborado pelos autores (2018).

* Referenciados em outros estudos bibliométricos.

Nos resultados apresentados, os estudos de Liu (2008) e Chen e Yuan (2007) são os mais citadas (13 e 11 citações respectivamente), abordando o desenvolvimento de um modelo estratégico para alcance de tecnologia e estratégias de inovação empresarial no contexto chinês. Além destes, mais dois trabalhos entre os trinta mais citados (Xie \& White, 2006; Yu, Stough \& Nijkamp, 2009) fazem referência a aspectos empreendedorismo tecnológico na China. A predominância do contexto chinês na pesquisa de TE pode estar relacionada a alta taxa de adoção de TICs no continente asiático, o que promove e facilita a atividade empreendedora voltada à tecnologia.

Como terceiro estudo mais citado encontra-se a proposta de Shane e Venkataraman (2000) sobre as promessas do empreendedorismo como campo de pesquisa. Este e outros estudos listados (por exemplo Schumpeter,1942; Shane \& Venkataraman, 2003; Shane, 2003) foram igualmente identificados nos artigos bibliométricos de Ferreira, Reis e Miranda (2015), Ferreira et al. (2016) e Ratinho, Harms \& Walsh (2015) que abordaram respectivamente publicações em vinte anos de pesquisa de empreendedorismo (1981 a 2010), as vertentes temáticas do empreendedorismo tecnológico de 1986 a 2013 em periódicos e um estabelecimento da estrutura no campo de TE por meio da base de dados Scorpus. Assim, em termos comparativos, 23 dos 30 artigos mais citados apontados na tabela 3 também foram identificados por outros estudos de natureza bibliométrica o que fortalece os achados desta pesquisa e a relevância dos estudos que compõem a amostra.

\section{Considerações finais}

A presente pesquisa pautou-se em analisar as publicações de empreendedorismo tecnológico com foco no setor de Tecnologia da Informação e Comunicação (TIC) categorizados no período de 2006 a 2016 e, portanto, devido a essa limitação temporal e temática, a amostra utilizada consistiu em 30 artigos. Contudo, tal valor pode ser considerado suficiente e, mais do que isso, importante para entender melhor essa temática tão importante para o contexto empreendedor (Binnui \& Cowling, 2016; Ferreira et al., 2016).

Os trabalhos que compuseram a amostra foram analisados em termos de ano de publicação, periódico, palavras-chave, classificação da pesquisa empírica e listagem dos estudos mais referenciados no tangente as citações e co-citações. Nesse sentido, foi diagnosticado que oscilações na quantidade de publicações por ano pode ser uma realidade do 
campo, uma ênfase na perspectiva chinesa para a pesquisa em TE também foi identificada, o que pode fazer alusão a expressiva quantidade de empresas no setor de Tecnologia da Informação e Comunicação (TIC) na China, e a expressividade de citação de publicações seminais para o empreendedorismo nos artigos analisados. Tais achados permitiram então cumprir o objetivo estabelecido na pesquisa.

O empreendedorismo tecnológico, como fora citado ao decorrer do texto, além de ser um termo mais recente, o mesmo é relativamente denso (Ratinho, Harms \& Walsh, 2015) e, além disso, considera-se como um dos temas de empreendedorismo mais estudados na última década (Ferreira, Reis \& Miranda, 2015). Diante disso, este estudo apresenta como limitação a falta de uma perspectiva amostral mais expressiva, levando em consideração outros estudos de natureza similar. Porém, acredita-se que os critérios estabelecidos para a composição da amostra restringiram o número de artigos a serem buscados e utilizados por meio da base de dados enfocada. Consequentemente, como sugestão para estudos futuros espera-se que outros pesquisadores investiguem a perspectiva do empreendedorismo tecnológico por meio das TICs em outras bases de dados, permitindo a ampliação e contraste com os achados deste trabalho.

\section{REFERÊNCIAS}

Acs, Z.J., Lászlo, S., Autio, E.\& Lloyd, A. (2017). Global Entrepreneurship Index (GEINDEX). The Global Entrepreneurship and Development Institute, Washington, D.C., USA. Disponível em: <https://thegedi.org/global-entrepreneurship-and-development-index/>. Acesso em: 22 mai. 2017

Araújo, C. A. (2006). Bibliometria: evolução histórica e questões atuais. Em questão, 12(1), 11-32.

Autio, E., Kenney, M., Mustar, P., Siegel, D., \& Wright, M. (2014). Entrepreneurial innovation: The importance of context. Research Policy, 43(7), 1097-1108.

Bailetti, T., (2012). Technology entrepreneurship: overview, definition, and distinctive aspects. Technology Innovation Management Review. 2, 5-12.

Baker, T., Gedajlovic, E., \& Lubatkin, M. (2005). A framework for comparing entrepreneurship across nations. Journal of International Business Studies, 36(5), 492-504

Binnui, A., \& Cowling, M. (2016). A conceptual framework for measuring entrepreneurship and innovation of young hi-technology firms. GSTF Journal on Business Review (GBR), 4(3), $32-47$.

Boettke, P. \& Coyne, C. (2009). Context matters: Institutions and entrepreneurship. Foundations and Trends in Entrepreneurship, 5(3), 135-209. 
Brown, R., \& Mason, C. (2014). Inside the high-tech black box: A critique of technology entrepreneurship policy. Technovation, 34(12), 773-784.

Carter, S., Tagg, S., \& Dimitratos, P. (2004). Beyond portfolio entrepreneurship: Multiple income sources in small firms. Entrepreneurship and Regional Development, 16(6), 481-499

Coordenação de Aperfeiçoamento de Pessoal de Nível Superior [CAPES]. Disponível em: $<$ http://www-periodicos-capes-gov-br.ez20.periodicos.capes.gov.br/>. Acesso em: 20 jun. 2017

Colovic, A., \& Lamotte, O. (2015). Technological Environment and Technology Entrepreneurship: A Cross-Country Analysis. Creativity and Innovation Management, 24(4), 617-628.

Creswell, J. W. Projeto de pesquisa: métodos qualitativo, quantitativo e misto. Tradução Magda Lopes. 3. ed. Porto Alegre: Artmed, 2010.

Cruz, C., Marques, A., Silva, R., \& Cogan, S. (2010). Teoria das Restrições: um estudo bibliométrico da produção científica apresentada no congresso brasileiro de custos (19942008). Associação Brasileira de Custos, 5(1), 152-175.

Dupuis, A. \& de Bruin, A. (2003). Community entrepreneurship. In A. Dupuis \& A. de Bruin (Eds.), Entrepreneurship: New perspectives in a global age (pp. 109-127). Aldershot: Ashgate.

Feldman, M.P., Francis, J., \& Bercovitz, J. (2005). Creating a cluster while building a firm: Entrepreneurs and the formation of industrial clusters. Regional Studies, 39(1), 129-141.

Ferreira, M. P., Reis, N. R., \& Miranda, R. (2015). Thirty years of entrepreneurship research published in top journals: analysis of citations, co-citations and themes. Journal of Global Entrepreneurship Research, 5(1), 17.

Ferreira, J. J., Ferreira, F. A., Fernandes, C. I., Jalali, M. S., Raposo, M. L., \& Marques, C. S. (2016). What do we [not] know about technology entrepreneurship research?. International Entrepreneurship and Management Journal, 12(3), 713-733.

Gartner, W.B., Davidsson, P., \& Zahra, S. (2006). Are you talking to me? The nature of community in entrepreneurship scholarship. Entrepreneurship Theory and Practice, 30(3), $321-331$

Galindo, M. Á., \& Méndez, M. T. (2014). Entrepreneurship, economic growth, and innovation: Are feedback effects at work? Journal of Business Research, 67(5), 825-829. 
Guimaraes, S. M. K.; Azambuja, L. R. (2010). Empreendedorismo high-tech no Brasil: condicionantes econômicos, políticos e culturais. Sociedade e Estado., 25 (1), 93-121.

Giriuniene, G., Giriunas, L., \& Cernius, G. (2016). Identification Research of the Concept of Entrepreneurship: The Theoretical Aspect. International Journal of Economics and Financial Issues, 6(6S), 162-167.

Hackman, R. (2003). Learning more by crossing levels: Evidence from airplanes, hospitals, and orchestras. Journal of Organizational Behavior, 24, 905-922

Johnstone, H. \& Lionais, D. (2004). Depleted communities and community business entrepreneurship: Revaluing space through place. Entrepreneurship and Regional Development, 16(3), 217-233.

Klapper, L., Lewin, A., \& Delgado, J.M. (2009). The impact of the business environment on the businesscreation process. Policy Research Working Paper 4937. Washington, DC: The World Bank.

Minniti, M. (2003). Entrepreneurship studies: A stocktaking. In R. Koppl (Ed.), Austrian economics and entrepreneurial studies. Advances in Austrian Economics (Vol. 6, pp. 9-37). Amsterdam: Elsevier.

Mosey, S., Guerrero, M., \& Greenman, A. (2017). Technology entrepreneurship research opportunities: insights from across Europe. The Journal of Technology Transfer, 42, 1-9.

Petti, C., \& Zhang, S. (2011). Factors influencing technological entrepreneurship capabilities: Towards an integrated research framework for Chinese enterprises. Journal of Technology Management in China, 6(1), 7-25.

Ratinho, T., Harms, R., \& Walsh, S. (2015). Structuring the Technology Entrepreneurship publication landscape: Making sense out of chaos. Technological forecasting and social change, 100, 168-175.

Ribeiro, H. C., \& Corrêa, R. (2014). 10 Anos de Pesquisa da Revista Brasileira de Inovação Sob a Ótica da Bibliometria e da Rede Social. Administração: Ensino e Pesquisa, 15(4), 729767.

Sampieri R. H.; Collado C. F.; Lucio P. B., (2006). Metodologia de pesquisa. Trad. Fátima Conceição Murad, Melissa Kassner, Sheila Clara Dystyler Ladeira. 3 ed. São Paulo: Mac Graw Hill. 
Samuelsson, M., and P. Davidsson. (2009). "Does Venture Opportunity Variation Matter? Investigating Systematic Process Differences between Innovative and Imitative New Ventures" Small Business Economics 33 (2): 229-255.

Schumpeter, J. A. (1934). The theory of economic development: An inquiry into profits, capital, credit, interest, and the business cycle. New Jersey: Transaction publishers.

Schumpeter, J. (1942). Capitalism, Socialism and Democracy. New York: Harper.

Shane, S. A. 2003. A General Theory of Entrepreneurship. Cheltenham: Edward Elgar.

Shane, S., and S. Venkataraman. (2000). The Promise of Entrepreneurship as a Field of Research. Academy of Management Review. 25 (1): 217-226.

Shane, S., \& Venkataraman, S. (2003). Guest editors' introduction to the special issue on technology entrepreneurship. Research policy, 32(2), 181-184.

Soriano, D. R., \& Huarng, K. H. (2013). Innovation and entrepreneurship in knowledge industries. Journal of Business Research, 66 (10), 1964-1969.

Spiegel, M., \& Marxt, C. (2011, December). Defining Technology Entrepreneurship. In Industrial Engineering and Engineering Management (IEEM), 2011 IEEE International Conference on (pp. 1623-1627). IEEE.

Stevenson, H. H, (1983). A perspective on entrepreneurship. Harvard Business School Working Paper. 9-384-131.

Venkataraman, S. (1997). The distinctive domain of entrepreneurship research: An editor's perspective. In J. Katz \& R. Brockhaus (Eds.), Advances in entrepreneurship, firm emergence, and growth, vol. 3: 119-138. Greenwich, CT: JAI Press.

Venkataraman, S. (2004). Regional transformation through technological entrepreneurship. Journal of Business Venturing, 19(1), 153-167.

Walter, S., and J. Block. (2016). Outcomes of Entrepreneurship Education: An Institutional Perspective. Journal of Business Venturing. 31 (2): 216-233.

Welter, F. (2011). Contextualizing entrepreneurship - conceptual challenges and ways forward. Entrepreneurship Theory and Practice, 35(1), 165-184. 